\title{
Culture in ELT: A probe into Iranian EFL teachers' perspectives
}

\author{
Jalali, Sara $\bowtie$ \\ Urmia University, Iran (s.jalali@urmia.ac.ir) \\ Tamimi Sa'd, Seyyed Hatam \\ Urmia University, Iran (Shtamimi90@gmail.com)
}

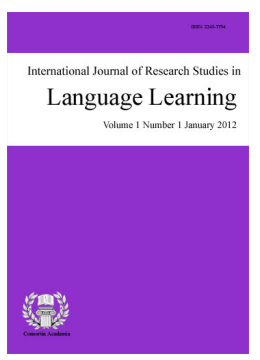

ISSN: 2243-7754

Online ISSN: 2243-7762

Received: 24 October 2013

Revised: 16 November 2013 DOI: $10.5861 /$ ijrsll.2013.599

Accepted: 17 November 2013

OPEN ACCESS

\section{Abstract}

The current study aimed at delving into EFL teachers' perspectives towards culture and the different sources and procedures of teaching it in the classroom with a focus on the qualifications of the teachers. The participants consisted of 95 Iranian language teachers. For the purposes of this study, the participants were divided into three qualification groups: MA in English, English Students of MA and Other. To explore the participants' perspectives on the issue of culture in ELT, the researchers used a questionnaire. One-way ANOVA indicated: a) significant differences between the groups of MA holders and other groups with regard to the teachers' use of various materials in teaching culture; b) no significant differences among the participant groups regarding the importance of integrating culture in language pedagogy, the frequency of discussing culture in EFL classes, the teachers' perceptions of the effect of culture on the learners' motivation, and the aspects emphasized by teachers in teaching culture; and c) significant differences among MA holders and other groups in their emphasis on the United States as their focus of attention when teaching culture. The results indicated that the teachers' qualifications might not be an influential factor in determining their perspectives on the issue of culture in language teaching.

Keywords: second/foreign language teaching; L2 Motivational Self System; Iranian high schools; case study 


\section{Culture in ELT: A probe into Iranian EFL teachers' perspectives}

\section{Introduction}

Culture is a notoriously difficult term to define due to the fact that "it covers an extremely wide range of ideas, thoughts, beliefs, views, values, manners, customs, and institutions" (Horibe, 2008, p. 223). However, there are two major perspectives towards the concept of culture. The first of these is perceiving culture as the accumulation of facts about a community (Brooks, 1975). According to this early perspective, culture is seen to be a static invariant behavior of a people whose participation in the generation of culture is not appreciated. However, a more recent perspective towards culture acknowledged the role of the individual in the creation of culture; therefore, it perceives culture to be a changeable entity which is subject to human interaction and communication. This radical change in perspective is identified by "conceptual shifts from culture-specific to culture-general models of intercultural competence, cultural stereotypes to cultural generalizations, cultural absolutes to cultural variations (within and across cultures), and culture as distinct from language to culture as integral to language" (Paige, Jorstad, Siaya, Klein, \& Colby, 2003, p.176).

Different people interpret culture in different ways. Chastain (1988) presents "the way people live" as the definition of culture from an anthropological perspective (p. 302). Spencer-Oatey (2000 cited in Ogiermann, 2009, p. 25) defines culture as "a fuzzy set of attitudes, beliefs, behavioural conventions, and basic assumptions and values that are shared by a group of people, and that influence each member's behaviour and each member's interpretations of the 'meaning' of other people's behaviour". Karabinar (2012) perceived language and culture to be "part of a whole" and "firmly connected to each other" in a way that "one cannot exist without the other" (p. 114). Along the same line, Kramsch (1991, p. 217) considers language and culture to be "inseparable and constitute a single universe or domain of experience". Furthermore, Hui (2010, p. 79) contends "language is a reflection of culture and culture is a reflection of language". These citations all demonstrate that language and culture are so integrated that the non-existence of one, endangers the existence of the other.

With the current rush towards globalization, the need for gaining a better understanding of the language and culture of foreign people is developing among language learners. English has gained overwhelmingly in popularity due to its unrivalled permeation in every scientific and non-scientific aspect of human life; therefore, elevating the EFL learners' awareness of cultural facets of English people seems a necessity.

\subsection{Background}

Recently, the significance of expanding the language learners' awareness of the cultural aspects of the target language has been widely recognized. Foreign language learning is considered to be "an intercultural subject matter" which "entails an increase in learners' familiarity with that language's cultural background, an expansion of the learner's cultural awareness and intercultural competence" (Sercu, García, \& Prieto, 2004, p. 86). The term 'intercultural competence' emerged out of this importance. Intercultural competence (IC) is spelled out to be the "ability to interact effectively with people from cultures that we recognize as being different from our own" (Guilherme, 2000, p. 297). Due to the fickle nature of culture and its dependence on time and situation, it is by no means advisable for language teachers to adhere to a sole definition of culture provided by an individual.

Teachers' perceptions of the importance of cultural teaching and the strategies for integrating activities and learning materials which assist the language learners to boost their knowledge and understanding of the foreign culture, has been investigated by some researchers in the field. Byram and Risager (1999, cited in Hui, 2010) conducted a study in Europe to investigate how language teachers interpret culture teaching in language education. They found that teachers' understanding of culture teaching lacked depth, so they could not go beyond 
what was already presented in language textbooks about cultural aspects of a foreign country. Regarding the EFL teachers' perception of culture teaching, in a study by Sercu et al. (2004) a group of 35 Spanish EFL teachers were surveyed on a ranking question about the importance of teaching culture in a language class. They found out that Spanish teachers see culture teaching to be communicating information about the foreign culture. Information about daily life and routines of the target culture ranked first in importance as assessed by Spanish EFL teachers. However, Spanish teachers did not deem promoting students' own cultural understanding to be of much importance as this factor came last on the ranking. In the same study, teachers were asked to score some statements about their willingness to "interculturalise foreign language education" (p. 94). The results demonstrated that Spanish EFL teachers were completely willing to integrate intercultural aspects of the foreign culture in the language learning environment. In her study, Karabinar (2012) surveyed 155 English language teaching (ELT) instructors at Turkish universities on their attitudes towards teaching culture. The results of one part of the questionnaire about the topics used for culture teaching demonstrated that "tangible products of culture such as foods, dress, types of dwelling and toys" received priority among the instructors (p. 119). Literature, art, music, dance, and many others. which are "topics related to expressive products of culture" ranked second in priority for ELT instructors (p. 119).

Strategies to teach culture were also surveyed in the same study as another section of the questionnaire. The results demonstrated the fact that ELT instructors deemed "encouraging students to attend international exchange programs" to be the most significant strategy to teach culture in a language class (Karabinar, 2012, p. 120). Regarding the materials applied for cultural teaching, instructors chose textbooks and accompanying ancillaries, and supplementary instructional materials as their first and second preferences, respectively. In a study conducted by Hui (2010) in Xinjiang, the teaching activities and practices used by language teachers in cultural teaching was investigated. He found that the first source to teach culture was through textbooks. Reciting dialogues, using audiotapes, and culture loaded new words came second, third, and forth, respectively. More recently, a study by Chang (2013) revealed that EFL teachers in kindergartens in Taiwan assumed that introducing the Western culture resulted in a broader world perspective as one of the participants had stated.

\subsection{Significance of the study}

The present study is an attempt to, as fully as possible, scrutinize the issue of culture in language pedagogy in the Iranian setting. The significance of the study lies in the fact that it touches upon a wide range of issues surrounding culture in ELT which have mostly been either neglected or only partially attempted, particularly in Iran. It is hoped that studies of the present type would help broaden our understanding of how language teachers perceive, deal with and teach culture in Iran. In addition, this information will help the stakeholders to choose some strategies in order to improve the situation.

This study has also taken into account the participants' academic qualifications as the criterion based on which the participants were divided into three groups to obtain the appropriate data. It is motivated by the scarcity of research studies on the issue of culture in language pedagogy in Iran.

\subsection{Research questions}

Considering the fact that the academic qualifications were the criteria based on which the participants were divided into the aforementioned qualification groups, the following research questions were formulated and sought to be answered:

$>$ Q1: Is there any significant difference among the qualification groups with regard to their perceptions of the importance of culture, frequency of discussing culture and the effect of teaching culture on the learners' motivation?

$>$ Q2: Is there any significant difference among the qualification groups with regard to the materials and activities considered useful for teaching culture? 
$>$ Q3: Is there any significant difference among the qualification groups with regard to the importance attached to the aspects of culture?

Q4: Is there any significant difference among the qualification groups with regard to the countries emphasized or referred to most frequently as sources of teaching culture?

$>$ Q5: What are the sources employed most frequently by Iranian EFL teachers to teach culture?

\section{Method}

\subsection{Participants}

The participants of the study, both students and holders of BA/BSc, MA/MSc and PhD, consisted of $95 \mathrm{EFL}$ teachers, 36 males and 59 females, whose age ranged from 20 to 53 (mean $=28$ ) and teaching in various language institutes in Iran. In general, these teachers' teaching experience ranged from 1 to 21 years (mean $=5.6$ ). For the purposes of appropriate data analysis, the participants were divided into three groups of qualifications: MA students of English, MA in English, and Other consisting of students or holders of BA in English, BSc and $\mathrm{PhD}$. The data regarding the participants' academic qualifications are summarized in Table 1.

\section{Table 1}

Descriptive statistics of the participants' qualifications

\begin{tabular}{lll}
\hline Group & Frequency & Percentage \\
\hline MA students of English & 33 & 34.7 \\
MA in English & 36 & 37.9 \\
Other & 26 & 27.4 \\
Total & 95 & 100 \\
\hline
\end{tabular}

It is worth noting that almost half of the participants were contacted via email as they lived and studied in various cities of Iran. This fact strengthens the generalizability of the results as the participants did not belong to a certain city but came from a wide range of cities. Another factor that adds to the generalizability of the findings is the fact that the participants were not limited to a certain academic group, say, BA or MA students, but rather held differing academic degrees as mentioned in the previous paragraph.

\subsection{Instruments}

To gather the data, the researchers utilized the Teacher Questionnaire employed in Saluveer (2004) which had been devised and whose relaibality had been checked by one of the researchers as a data collection tool for master's thesis. The questionnaire consists of 8 sections that deal with different aspects of culture such as the usefulness of certain materials and activities to be used in teaching culture, the importance of certain aspects of culture, the materials that the participants use when teaching culture in ELT, etc. In general, this instrument proved a very useful data collection tool for the present study because of its comprehensiveness (See Appendix A). The questionnaire was analyzed by two university professors, with the first author of the study as a third specialist, specialized in applied linguistics as to its content validity. Finally, the researchers applied changes, based on the suggestions of the specialists, to the Likert scale of the questionnaire which were deemed more appropriate for eliciting the required data.

\subsection{Procedure and data analysis}

The data collected by the use of the questionnaire were analyzed using the SPSS software (Statistical Package for Social Sciences), version 20. One-way ANOVA, discriptive statistics, percentages and frequency counts were the common statistics utilized to appropriately report the data. 


\section{Results}

\subsection{Findings of the study}

The current study set about investigating the different aspects, sources, materials and activities involved in the teaching of culture in ELT as practised by 95 Iranian EFL teachers. The results are presented below.

\section{Three Issues on Culture in ELT}

The first research question addressed three issues that were dealt with in the first three sections of the questionnaire which required the EFL teachers to venture their opinions on three issues surrounding culture: (1) the importance of integrating the teaching of culture into foreign language classes, (2) the frequency with which they discuss culture-related issues in their English classes and (3) the effect of learning the language with some background knowledge in culture on the students' motivation and interest in language learning. The results for these three sections are summarized in Tables 2 and 3 below.

\section{Table 2}

One-way ANOVA for the First Three Sections of the Questionnaire

\begin{tabular}{llllll}
\hline \multicolumn{2}{c}{ Section } & df & Mean Square & F & Sig. \\
\hline \multirow{2}{*}{ Integration of culture } & Between Groups & 2 & .34 & 1.05 & .36 \\
& Within Groups & 92 & .33 & & \\
& Total & 94 & & .10 & .90 \\
Frequency of discussing & Between Groups & 2 & .04 & .10 & \\
culture & Within Groups & 91 & .36 & & .31 \\
& Total & 93 & & .35 & \\
Interest in language learning & Between Groups & 2 & .18 & & \\
& Within Groups & 91 & .52 & & \\
& Total & 93 & & & \\
\hline
\end{tabular}

$$
\begin{aligned}
& \mathrm{F}_{\text {section } 1}(2,92)=1.05 ; \mathrm{p}>0.05 \\
& \mathrm{~F}_{\text {section2 }}(2,91)=0.10 ; \mathrm{p}>0.05 \\
& \mathrm{~F}_{\text {section3 }}(2,91)=0.35 ; \mathrm{p}>0.05
\end{aligned}
$$

As shown in Table 2 above, no significant difference was observed with regard to the items chosen by the participant groups.

Table 3

The Most Frequently Selected Response for the First Three Questionnaire Sections

\begin{tabular}{llll}
\hline Group & Section 1 & Section 2 & Section 3 \\
Other & Yes, important (68\%) & $\begin{array}{l}\text { Sometimes (once a week) } \\
(68 \%)\end{array}$ & $\begin{array}{l}\text { Yes, with significant difference } \\
(64 \%)\end{array}$ \\
$\begin{array}{l}\text { MA students of } \\
\text { English }\end{array}$ & $\begin{array}{l}\text { Yes, important } \\
(59.9 \%)\end{array}$ & $\begin{array}{l}\text { Sometimes (once a week) } \\
(56.8 \%)\end{array}$ & $\begin{array}{l}\text { Yes, with significant difference } \\
(56.8 \%)\end{array}$ \\
MA in English & $\begin{array}{l}\text { Yes, very important } \\
(57.6 \%)\end{array}$ & $\begin{array}{l}\text { Sometimes (once a week) } \\
(45.5 \%)\end{array}$ & $\begin{array}{l}\text { Yes, with significant difference } \\
(72.7 \%)\end{array}$ \\
\hline
\end{tabular}


As can be seen in Table 3, the teachers were equally cognizant of the importance of the first three issues in teaching culture.

\section{Usefulness of Materials and Activities in Teaching Culture}

The second research question dealt with the the usefulness of each of the materials and activities specified in teaching culture. This was addressed in section 4 of the questionnaire, consisting of 12 items including such materials as lectures, watching videos, role plays, drama, etc. The results for the differences appear in Table 4 below.

\section{Table 4}

The Results for Significant Differences of Materials Usefulness Evaluation

\begin{tabular}{lll}
\hline Group & Watching videos & Drama \\
\hline Other & Useful $^{*}(44 \%)$ & Least useful* $(56 \%)$ \\
MA students of English & Very useful $(56.8 \%)^{*}$ & Useful $(45.9 \%)$ \\
MA in English & Very useful $^{*}(66.7 \%)$ & Useful ${ }^{*}(39.4 \%)$ \\
\hline
\end{tabular}

As shown in Table 4 above, the results indicated that there were significant differences with regard to 'watching videos' $(\mathrm{p}$-value $=.02)$ and 'drama' ( $\mathrm{p}$-value $=.02$ ) between the groups of Others and MA in English.

Regarding the materials and activities useful in teaching culture in ELT, it was tried that the most frequent item chosen equally and with no significant difference by the three groups of Others, English students of MA and MA in English be presented here in Table 5.

\section{Table 5}

The Most Frequent Item of Materials Chosen Equally by the Participant Groups

\begin{tabular}{ll}
\hline Materials/Activities & Item Chosen \\
\hline Lectures & Useful \\
Discussions on cultural differences and similarities & Very useful \\
Listening to songs and discussing the lyrics & Useful \\
Listening to radio programs & Useful \\
Reading and discussing newspaper/magazine articles & Useful \\
Talking about current events & Very useful \\
Reading authentic texts (short stories, poems) & Useful \\
Role plays & Useful \\
Doing projects & Useful \\
Culture capsule & Very useful \\
\hline
\end{tabular}

As can be seen from Table 5 above, interestingly enough, no material or activity has been deemed unuseful in teaching culture, but all of them, except three activities, were deemed 'useful'. Furthermore, three activities, namely 'discussions on cultural differences and similarities', 'talking about current events' and 'culture capsule' were considered 'very useful'.

\section{The Importance of Aspects of Culture}

The next section of the questionnaire, section 5, consisted of 16 items dealing with such aspects of culture as geography, history, costumes and festivals, patterns of politeness, among others and required the participants to assess the importance of these aspects of culture once they incorporated them in ELT. This was addressed in the third research question and the results for this part are sumarized in Table 6. 


\section{Table 6}

The Importance of the Aspects to be Incorporated in Teaching Culture

\begin{tabular}{lllllll}
\hline & & & & \\
Item & & & & & \\
\end{tabular}

No significant differences were observed among the groups with regard to the importance of the various aspects of culture in ELT. The participants' ideas were very close to eachother.

\section{Aspects of Importance in the Teaching of Culture}

Regarding the importance of the different aspects of culture in teaching it in ELT, it was attempted that the response chosen most frequently and with no significant difference by the three groups of Others, English students of MA and MA in English be presented here in Table 7.

Table 7

The Most Frequent Item Chosen by the Groups for Aspects of Culture

\begin{tabular}{ll}
\hline Materials/Activities & Most Frequent Response \\
\hline Geography & Least important \\
History & Important \\
Monarchy & Least important \\
Literature and art & Important \\
Music & Important \\
Government and political institution & Least important \\
Law and order & Least important \\
Education and schools & Important \\
Food & Important \\
Youth life & Very important \\
\hline
\end{tabular}

Table 7 shows that the least important aspects of culture were found to be geography, monarchy, government and political institution, law and order. The common feature of these aspects, except for geography, is the fact that all of these aspects concern politics which is not mainly an appealing theme to language teachers. Geography, however, could have been a suitable candidate for teaching culture; nevertheless, the results in Table 7 stand in contrast to our first expectation. The interesting point is that the only 'very important' aspect is youth life. The reason for this can lie in the fact that this serves as the most relevant theme to language learners. Included in this area are such subjects as clothes, foods, fashion, and so on which are highly attractive to the language learners who are mostly from lower age ranges. 


\section{Whose culture? Countries Emphasized Least and Most}

The next section explored the extent to which the participants stressed the English speaking countries, including the US, UK, Canada and other countries, as sources of culture when they teach culture and language. This issue was dealt with in the fourth reserach question which sought to explore to what percentage the participants emphasized the countries mentioned as references for teaching culture. Table 8 demonstrates the percentages of emphasis on each country that were provided by the participants.

\section{Table 8}

Percentage of Emphasis on Countries as Sources of Culture in ELT

\begin{tabular}{lllll}
\hline $\begin{array}{l}\text { Country } \\
\text { Group }\end{array}$ & US & UK & Australia & Other countries \\
\hline Other & $64.92 \% \%^{*}$ & $30.08 \%$ & $7.80 \%$ & $5.32 \%$ \\
MA students of English & $54.54 \%$ & $27.68 \%$ & $8.51 \%$ & $4.22 \%$ \\
MA in English & $48.82 \% \%^{*}$ & $28.58 \%$ & $5.76 \%$ & $7.76 \%$ \\
Totals & $55.28 \%$ & 28.62 & $7.37 \%$ & $5.74 \%$ \\
\hline
\end{tabular}

The distribution of percentages among the countries mentioned in Table 8 indicated that the US is the most emphasized point of departure in teaching culture (55.2\%). As can be seen, the least emphasis was laid on the other countries than US, UK and Australia. Even Australia, although it is an English-speaking country, received only minimal attention $(7.37 \%)$.

Table 9

One-way ANOVA Results for the Participant Groups

\begin{tabular}{llllll}
\hline & & df & Mean Square & F & Sig. \\
\hline \multirow{4}{*}{ UK } & Between Groups & 2 & 43.18 & .11 & .90 \\
& Within Groups & 92 & 391.83 & & \\
& Total & 94 & & & \\
\multirow{4}{*}{ US } & Between Groups & 2 & 1860.69 & 3.16 & .05 \\
& Within Groups & 92 & 589.78 & & \\
& Total & 94 & & & \\
\multirow{4}{*}{ Australia } & Between Groups & 2 & 69.40 & .70 & .50 \\
& Within Groups & 92 & 99.32 & & \\
& Total & 94 & & & \\
\multirow{2}{*}{ Others } & Between Groups & 2 & 112.33 & 1.52 & .23 \\
& Within Groups & 92 & 74.08 & & \\
& Total & 94 & & & \\
\hline
\end{tabular}

The results of ANOVA indicated that there were significant differences between the participant groups of Other and MA in English with regard to their emphasis on the US as their reference in teaching culture.

\section{Sources of Teaching Culture}

This study also explored the sources that Iranian EFL teachers used to teach culture, dealt with in the fifth research question of the study. They were required to select from among the sources that were presented to them. The findings are presented in Figure 1. 


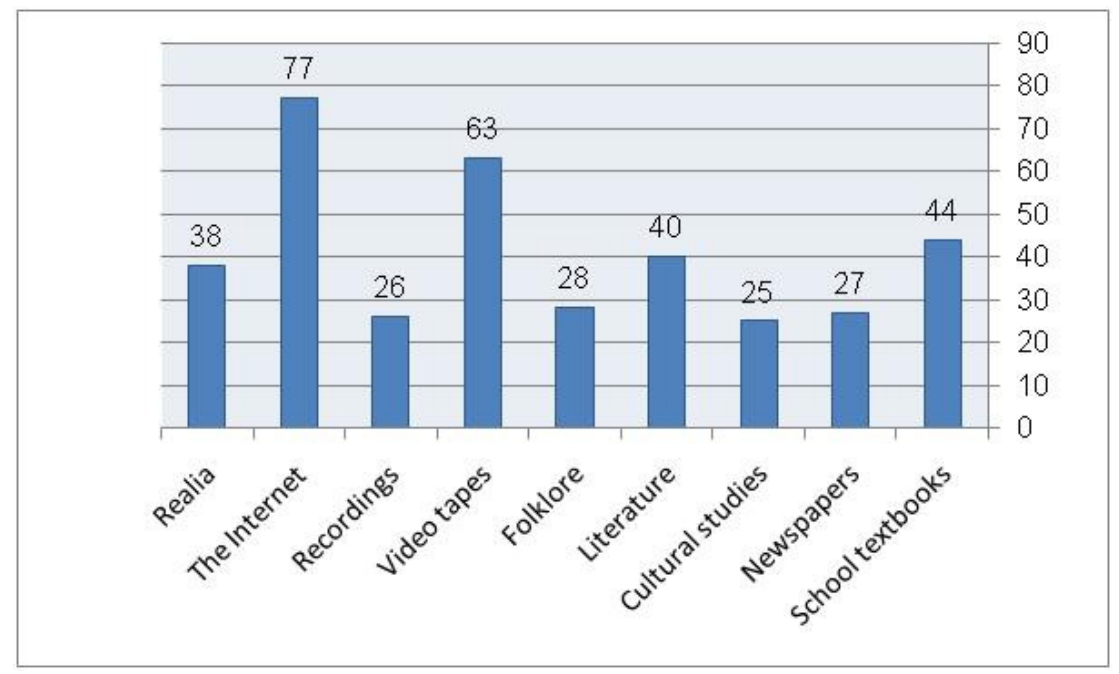

Figure 1. Frequency of teachers using each source of teaching culture in ELT

As can be seen in Figure 1, the Internet (77), video tapes (63) and school textbooks (44) constituted the three most significant sources of teaching culture. The least frequent sources, on the other hand, were recordings (26), folklore (28), cultural studies (25) and newspapers (27).

A final point that was examined was the extent to which the textbooks the teachers employed offered enough material for discussing culture related issues. The responses revealed that only 15 teachers $(15.8 \%)$ viewed the materials to be adequate in this regard, with 7 (7.4\%) teachers assuming that the materials offered quite a lot in the area of culture. A number of $55(57.9 \%)$ teachers selected the 'to some extent' option of the Likert scale while 18 (18.9\%) teachers' responses to this question were negative.

\section{Discussion}

The current study was carried out in the hope of scrutinizing the issue of culture among Iranian EFL teachers from different aspects. As for the first three issues, namely (1) the importance of integrating the teaching of culture into foreign language classes, (2) the frequency with which they discuss culture-related issues in their English classes and (3) the effect of learning the language with some background knowledge in culture on the students' motivation and interest in language learning, the results, reported in Tables 2 and 3, showed no significant differences among the the qualification groups. This finding, in turn, demonstrates that Iranian language teachers, regardless of their academic qualifications, are equally aware of the beneficial effect of culture on language learning. The effect of cultural background on language learning was explored and confirmed by Mekheimer (2011) in a case study of an advanced EFL student in Saudi Arabia. In addition, all three participant groups believed that the teaching of culture could have a motivating effect on the language learners. This finding is consistent with and corroborated by Rashidi and Soureshjani (2011) whose study indicated that teaching culturally-based texts had a remarkable effect on Iranian EFL learners' motivation and performance on reading comprehension. In general, the results in this part do not demonstrate any considerable difference among the participant groups. The frequency of discussing cultural themes in EFL classes was found to be of relative importance, however. This might have been caused by the limitations with which the teachers are normally faced when teaching culture.

Concerning the usefulness of the materials and activities aforementioned, the findings, reported in Tables 4 and 5, showed that the participants assumed that all the activities and materials mentioned are useful in teaching culture, indicating the Iranian EFL teachers' full cignizance of the variety of sources that they have in this regard. Significant differences were observed among the groups regading two materials: 'watching videos' and 'drama'. 
The results may be suggestive of the fact that the emphasis on 'watching videos' as one of the most useful sources for teaching culture can emanate from the fact that videos are not only widespread and can be easily made available but also they deal with the visual sense and therefore, appeal to the viewer to a large extent. The importance of drama, as an aspect of literature, has been highlighted in a study by Khatib, Rezaei and Derakhshan (2011) of literature in teaching culture in the EFL classroom. In this regard, one reason for the difference of opinion between the Other group and the two other groups can be the fact that the former group consists mainly of students who had been majoring in areas other than English language and literature and therefore, may not have a deep understanding of the importance and benefits of drama in teaching culture. The same might be true of the difference in the responses regarding 'watching videos'. The ample opportunity for using videos from the Internet and the increasing benefits are discussed by Watkins and Walkins (2011). The findings also show that the three 'very useful' activities selected are: discussions on cultural differences and similarities, talking about current events, and culture capsule. The common feature about these activities is the fact that in all of them the language learners are required to 'speak' which is, for many teachers if not all, the most important skill to be learnt. Furthermore and more importantly, the critical ability of the learners is tapped in these activities. It is worth mentioning that these findings are remarkably consistent with Saluveer's (2004) own findings, indicating that there is a universal tendency among language teachers across the globe to attach considerable significance to all dimensions of culture.

As regards the importance of the aspects of culture in teaching culture, the results, Tables 6 and 7, again demonstrated no significant difference among the participant groups, a finding that might emanate from the fact that in the teachers' view, the importance of these aspects is not an all-or-nothing matter and therefore, all of them can be of significance although the degree of this significance is not exactly the same. As was true of the materials and activities, the participants' responses demonstrated once again that all aspects were almost equally significant in teaching the target culture.

Another issue examined was the countries emphasized as references in teaching culture which revealed that the US was the most favored English-speaking country for teaching culture (see Tables 8 and 9). In line with Naji and Pishghadam (2013) who cited studies stating that the English-speaking culture is perceived to be superior, this finding clearly shows the dominance of the US hegemony throughout the world of ELT. In an investigation of culture as perceived by language learners, Prodromou (1992) indicated that only $26 \%$ of the participants favored 'American life'. This finding is in contrast with how teachers perceived American culture in this study. The mismatch between the perceptions of language learners and those of language teachers is potential point of conflict. Another important finding is the significant difference between the groups of Other and MA in English, with the former group emphasizing the US more considerably than the latter. It is possible that the MA in English group has developed a deeper and more critical understanding of the role of culture of other countries to be incorporated in ELT than the Other group since the Other group consists mainly of students of majors other than English, that is, BSc and MSc.

The last issue dealt with here was that of the sources used in teaching employed to teach culture. It can be speculated that the widespread use and the increasing immediate availability have been the reasons for selecting the Internet, video tapes and school textbooks as the most frequently used sources (Figure 1). Watkins and Wilkins (2011), for instance, in a discussion of using YouTube in the EFL classrooms, argued that it could be utilized not only to teach language skills but to enhance learner autonomy, discuss cultural matters and expose learners to World Englishes as well. It sould be noted that although the results indicated relative use of textbooks, they are inconsistent with Dahmardeh and Wray (2011) whose study demonstrated that culture "appears to play no role in either the textbooks or the English language teaching programme" (p. 265). The prominence of textbooks in teaching culture was also confirmed by Hui's (2010) study in which textbooks were found to be the first source of teaching culture mentioned by language teachers. Literature has also been the focus of attention of the teachers. In a discussion of the value of literary texts in EFL classrooms, Mackay (1982 cited in Thom, 2008, p. 120) made clear the point that "Literature can be useful in developing linguistic knowledge both on a usage and use level". At first glance, this finding comes as a surprise. It implies that teachers should be made 
aware of the considerable benefits of using these sources, especially regarding the use of newspapers which are one best source of authentic materials. For example, concerning the highly beneficial role that recordings can play in language teaching, Fox (2008) stated: "Teachers should also remember that many of their students now carry mobile phones capable of making adequate voice recordings, and these give readily available opportunities for students to record themselves or others outside the classroom" (p. 9).

\section{Conclusion and implications}

The current study aimed at exploring the issue of culture and including it in ELT from various aspects. The data were collected by the use of a questionnaire which tapped the numerous areas and aspects of teaching culture. In conclusion, the findings clearly indicated that Iranian EFL teachers were fully aware of the issue of culture, the ways and significance of incorporating it in EFL classrooms and the sources to do so. In conclusion, the study revealed that academic qualifications are determining factors in some respects such as their evaluations of the usefulness of the materials and activities and the countries referred to when teaching culture. The differences observed in the responses of the participant groups were not very considerable, demonstrating perhaps the equality of opportunity that the participants have had in getting acquainted with cultural aspects, sources, etc. Although this finding is a fortunate sign that the prime beneficiaries from this cultural awareness are the students in that they would develop their intercultural competence, further research is required to explore the extent to which EFL teachers are restricted in teaching culture and why.

Furthermore, the extent of emphasizing the first culture should be investigated as well. In conclusion, the teachers are expected to incorporate cultural issues in EFL classes as a means to, as Mao (2009) positd, "help students form a positive attitude in the bombardment of the exotic cultures" (p. 147). Valuing one's own and the target language culture is expected to result in what Khatib and Rezaei (2013) term "a more complete self" (p. 82).

Acknowledgment. The authors wish to extend their sincere thanks to all the English teachers who kindly assisted them in carrying out this study.

\section{References}

Brooks, N. (1975). The analysis of language and familiar cultures. In R. Lafayette (Ed.), The cultural revolution in foreign language teaching (pp. 19-31). Reports of the Northeast Conference on the Teaching of Foreign Languages. Lincolnwood, IL: National Textbook.

Chang, C. W. (2013). Exploring the beliefs of native and non-native English speaking kindergarten teachers in Taiwan. International Journal of Research Studies in Language Learning, 2(5), 3-16. http://dx.doi.org/10.5861/ijrsll.2012.171

Chastain, K. (1988). Developing second-language skills. USA: Harcourt Brace Jovanovich, Inc.

Dahmardeh, M., \& Wray, D. (2011).Culture and English language teaching in Iran. The Iranian EFL Journal, 7(5), 264-281.

Fox, A. (2008). Using podcasts in the EFL classroom. TESL-EJ, 11(44), 1-11.

Guilherme, M. (2000). Intercultural competence. In M. Byram (Ed.), Routledge encyclopaedia of language teaching and learning (pp. 297-300). London: Routledge.

Hui, H. (2010). An Investigation of teachers' perceptions of culture teaching in secondary schools in Xinjiang, China. Unpublished doctoral dissertation, Durham University.

Horibe, H. (2008). The place of culture in teaching English as an international language (EIL). JALT Journal, $30(2), 241-254$.

Karabinar, S. (2012).The attitudes of EFL teachers towards teaching culture and their classroom practices. Journal of Educational and Social Research, 2(2), 113-126.

Khatib, M., \& Rezaei, S. (2013). The portrait of an Iranian as an English language learner: A case of identity reconstruction. International Journal of Research Studies in Language Learning, 2(3), 81-93. 
Jalali, S. \& Tamimi Sa'd, S. H.

http://dx.doi.org/10.5861/ijrsll.2012.176

Khatib, M., Rezaei, S., \& Derakhshan, A. (2011). Literature in EFL/ESL classroom. English Language Teaching, 4(1), 201-208.

Kramsch, C. (1991). Culture in language learning: A view from the States. In K. de. Bot, R. B. Ginsberg, \& C. Kramsch (Eds.), Foreign language research in cross-cultural perspective (pp. 217-240). Amsterdam: John Benjamins.

MacKay, S. (1982). Literature in the ESL classroom. TESOL Quarterly, 16(4), 529. http://dx.doi.org/10.2307/3586470

Mao, W. (2009). Teaching culture within and beyond language. English Language Teaching, 2(4), 144-148.

Meidani, E. N., \& Pishghadam, R. (2013). Analysis of English language textbooks in the light of English as an International Language (EIL): A comparative study. International Journal of Research Studies in Language Learning, 2(2), 83-96.

Mekheimer, M. A. (2011). Impact of the target culture on foreign language learning: A case study. Cross-cultural Communication, 7(1), 43-52.

Ogiermann, E. (2009). On apologizing in negative and positive politeness strategies. The Netherlands: John Benjamins Publishing Company.

Paige, R. M., Jorstad, H., Siaya, L., Klein, F., \& Colby, J. (2003). Culture learning in language education: A review of the literature. In D. L. Lange, \& R. M. Paige (Eds.), Culture as the core: Perspectives on culture in second language education (pp. 173-236). USA: Information Age Publishing.

Prodromou, L. (1992). What culture? Which culture? Cross-cultural factors in language learning. ELT Journal, 46(1), 39-50. http://dx.doi.org/10.1093/elt/46.1.39

Rashidi, N., \& Soureshjani, K. H. (2011). The effect of teaching culturally-based texts on the Persian English as a foreign language (EFL) learners' motivation and reading performance. Journal of Languages and Culture, 2(8), 141-147.

Saluveer, E. (2004). Teaching culture in English classes. Unpublished masteral thesis, University of Tartu, Estonia.

Sercu, L., Méndez García, M. D. C., \& Prieto, P. C. (2004). Culture teaching in foreign language education. EFL teachers in Spain as cultural mediators. Porta Linguarum, 1, 85-102.

Thom, N. T. T. (2008). Using literary texts in language teaching. VNU Journal of Science, Foreign Languages, $24,120-126$

Watkins, J., \& Wilkins, M. (2011). Using YouTube in the EFL classroom. Language Education in Asia, 2(1), 113-119. http://dx.doi.org/10.5746/LEiA/11/V2/I1/A09/Watkins_Wilkins

\section{Appendix A}

\section{Teacher Questionnaire}

\section{Dear English teacher,}

The following questionnaire is an attempt to explore your perspective on the issue of "culture" in teaching English as a foreign language in your own practice of language teaching. The results and findings will be used for research purposes only! Your cooperation is highly appreciated.

Gender: Male $\square$

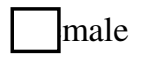

Age: ...

Years of English teaching experience: ... 
Your qualifications: ...

\begin{tabular}{|l|l|}
\hline & Student of BA \\
\hline & BA in English \\
\hline & Student of MA \\
\hline & MA in English \\
\hline & Student of PhD \\
\hline & PhD in English \\
\hline & BSc \\
\hline & MSc \\
\hline
\end{tabular}

\section{Please select the best option that fits you.}

1. Do you think it is important to integrate the teaching of culture into foreign language classes?

1) Yes, very important

2) Yes, important
3) Not important

4) It should be taught on a separate course

2. If the answer was yes then how often do you discuss culture-related issues in your English classes?

1) Often (in almost every lesson)

3) Rarely (once a month)

2) Sometimes (once a week)

4) Never

3) Do you think the students are more interested and motivated in learning the language with some background knowledge in culture?

1) Yes, with significant difference

2) Yes, but not much difference
3) No difference

4) Don't know

4) Which of the following do you consider most useful for teaching culture? Please rate from 1 to 4 for each selection. $1=$ Not useful, 2 = Least useful, 3 = Useful, 4 = Very useful

Please tick the appropriate box.

\begin{tabular}{|c|c|c|c|c|}
\hline & 1 & 2 & 3 & 4 \\
\hline \multicolumn{5}{|l|}{ Lectures } \\
\hline \multicolumn{5}{|c|}{ Discussions on cultural differences and similarities } \\
\hline \multicolumn{5}{|l|}{ Watching videos } \\
\hline \multicolumn{5}{|c|}{ Listening to songs and discussing the lyrics } \\
\hline \multicolumn{5}{|c|}{ Listening to radio programs } \\
\hline \multicolumn{5}{|c|}{ Reading and discussing newspaper/magazine articles } \\
\hline \multicolumn{5}{|c|}{ Talking about current events } \\
\hline \multicolumn{5}{|c|}{ Reading authentic texts (short stories, poems) } \\
\hline \multicolumn{5}{|l|}{ Role plays } \\
\hline \multicolumn{5}{|l|}{ Drama } \\
\hline \multicolumn{5}{|l|}{ Doing projects } \\
\hline Culture capsule & & & & \\
\hline
\end{tabular}

Note: Culture capsule is a brief description of culture followed by a discussion of the contrasts between culture in the first and second language. 
Jalali, S. \& Tamimi Sa'd, S. H.

5. What aspects of culture would you consider the most important to teach?

Please rate from 1 to 4 for each selection. $1=$ Not important, $2=$ Least important, $3=$ Important, $4=$ Very important

\begin{tabular}{|l|l|l|l|l|}
\hline & 1 & 2 & 3 & 4 \\
\hline Geography & & & & \\
\hline History & & & & \\
\hline Monarchy & & & & \\
\hline Costumes and festivals & & & & \\
\hline Literature and art & & & & \\
\hline Music & & & & \\
\hline Government and political institution & & & & \\
\hline Law and order & & & & \\
\hline Education and schools & & & & \\
\hline Family life & & & & \\
\hline Food & & & & \\
\hline Youth life & & & & \\
\hline Nationals symbols and stereotypes & & & & \\
\hline Rules of behavior & & & & \\
\hline Patterns of politeness & & & & \\
\hline Non verbal communication & & & & \\
\hline
\end{tabular}

6. When you teach areas named in 5, which country do you most focus on? Please indicate approximately in what proportions

1. United kingdom $\%$

2. United States .. \%

3. Australia ..$\%$

4. Other English speaking countries ..$\%$

7. What sources do you use when you teach culture? Please tick the ones you use

$>$ Newspapers

$>$ School textbooks

$>$ Cultural studies (e.g. British studies textbooks)

$>$ Literature

$>$ Folklore

$>$ Video tapes

$>$ Recordings

$>$ The internet

$>$ Realia (maps, brochures, tickets etc.)

8. In your opinion, do the textbooks you use offer enough material for discussing culture related issues?
1. Yes, quite a lot
2. Enough
3. To some extent
4. No 